\title{
Extension of the Constrained Gravitational Search Algorithm for Solving Multi-Reservoir Operation Optimization Problem
}

\author{
R. Moeini ${ }^{1 *}$ and M. Soltani-nezhad ${ }^{1}$ \\ ${ }^{1}$ Department of Civil Engineering, Faculty of Civil Engineering and Transportation, University of Isfahan, \\ Isfahan 81746-73441, Iran
}

Received 10 April 2018; revised 19 March 2019; accepted 21 October 2019; published online 14 May 2020

\begin{abstract}
In this paper the proposed constrained gravitational search algorithm (CGSA) is extended and used to solve multi-reservoir operation optimization problem. Tow constrained versions of GSA named partially constrained GSA (PCGSA) and fully constrained GSA (FCGSA) are outlined to solve this optimization problem. In the PCGSA, the problem constraints are partially satisfied, however, in the FCGSA, all the problem constraints are implicitly satisfied by providing the search space for each agent which contain s only feasible solution and hence leading to smaller search space for each agent. These proposed constrained versions of GSA are very useful when they are applied to solve large scale multi-reservoir operation optimization problem. The constrained versions of GSA are formulated here for both possible variables of the problem means considering water release or storage volumes as the decision variables of the problem and therefore first and second formulations of these algorithms are proposed. The proposed algorithms are used to solve the well-known four and ten reservoir operation optimization problems and the results are presented and compared with those of original form of the GSA and any available results in the literature. The results indicate the superiority of the proposed algorithms and especially FCGSA over existing methods to optimally solve large scale multi-reservoir operation optimization problem.
\end{abstract}

Keywords: multi-reservoir system, optimal operation, gravitational search algorithm, partially and fully constraint satisfaction.

\section{Introduction}

A large-scale regional water supply system usually includes several single or multi-reservoirs. Generally, a single reservoir system is designed for a single purpose such as water supply, hydropower generation or flood control. However, a multi reservoir system is designed for multiple purposes such as hydropower generation, flood control, navigation, fish and wildlife enhancement and water supply (agricultural, municipal and industrial) (Tu et al., 2003).

Finding optimal operation for multi-reservoir system is one of the most complex and challenging problems in the field of water resource planning and management in which it involves many variables, objectives and considerable risk and uncertainty. Nowadays, solving the multi-reservoir operation optimization problem is important throughout the world especially under water scarcity condition. Generally, finding optimal solution for reservoir operation optimization problem means that operator decides on the amount of water should be released now and also be retain-ed for future uses considering the variations of the inflows and demands. An appropriate operation can help to make good decision at any moment by using river flow

${ }^{*}$ Corresponding author. Tel.: 0098-31-37935293; fax: 0098-31-36699515. E-mail address: r.moeini@eng.ui.ac.ir (R. Moeini).

ISSN: $1726-2135$ print/1684-8799 online

(C) 2020 ISEIS All rights reserved. doi:10.3808/jei.202000434 range and determining reservoir characteristics. The problem of determining the optimal operation of a multi-reservoir system has been the subject of many researches in the past decades. However, the non-linearity and especially high-dimensionality of this problem make many difficulties for this optimization problem. Therefore, no completely satisfying solution has been obtained for this problem since in every research the simplified form of this problem has been defined and solved.

Generally, various optimization methods were proposed to solve reservoir operation optimization problem in which they were reviewed by many researchers such as Yeh (1985), Labadie (2004), Rani and Moreira (2010). Reviewing these researches shows that comprehensive methods that deal with a variety of multi-reservoir operation optimization problems are now available. Generally, selecting appropriate solving methods is dependent on the different elements such as operation tasks, available data, and mathematical form of objective function and constraint equations. It can be seen from the literature, various researchers have developed to find optimal operation of reservoir using different methods in which they are classified as dynamic programming (DP), linear programming (LP), non-linear programming (NLP), meta heuristic algorithms (such as genetic algorithm (GA), particle swarm optimization (PSO) algorithm, ant colony optimization algorithm (ACOA), honeybees mating optimization (HBMO) algorithm, simulated annealing (SA) and hybrid methods. Practically, numerous classical and traditional methods such as LP (Kuczera, 1989; Trezos, 1991; Tu etal., 2003; 
Reis et al., 2006; Azamathulla et al., 2008), NLP (Martin, 1983; Lund and Ferreira, 1996; Barros et al., 2003) and DP (Larson, 1968; Heidarietal., 1971; Murrayand Yakowitz, 1979; Yakowitz, 1982; Perera and Conder, 1998; Kumar and Baliarsingh, 2003; Mousavi and Karamouz, 2003; Goor et al., 2011; Liu et al., 2011; Jothiprakash et al., 2011; Zhao et al., 2012) have been used to solve multi-reservoir operation optimization problem. During the past four decades, a group of approximate methods, named meta heuristic algorithms, has been developed that they can explore the search space of the problem effectively and efficiently to prevent from trapping in a confined area of the search space. In other words, to partially overcome the limitations of traditional methods such as dimensionality problem, meta heuristic algorithms such as GA (Esat and Hall, 1994; Fahmy et al., 1994; Oliveira and Loucks, 1997; Wardlaw and Sharif, 1999; Tospornsampan et al., 2005a; Reis et al., 2006; Chen and Chang, 2007; Azamathulla etal., 2008; Malekmohammadi et al.,2009; Dariane and Momtahen, 2009; Jothiprakash et al., 2011; Hincal et al., 2011), HBMO algorithm (Bozorg Haddad et al., 2008; Afshar et al., 2010), PSO algorithm (Kumar and Reddy, 2007; FallahMehdipour et al., 2011; Ostadrahimi et al., 2012; Zhang et al., 2013),ACOA(Jalali,2005; Jalali et al., 2007; Moeini and Afshar, 2013; Moeini, 2014), SA (Wong and Wong, 1994; Tospornsampan et al., 2005b) have also been used to solve this problem.

Proposed methods mentioned above have successfully reduced the complexity of multi-reservoir operation optimization problem such as extent dimensions or alleviate the curse of dimensionality. It should be noted that, in this problem, the computational time cost extremely increases with increasing the number of reservoirs and operation time periods leading to large scale optimization problem. In other words, the computational time cost is absolutely intolerable when the scale of multi-reservoir system reaches a certain large degree. Therefore, the computational efficiency is a big challenge to solve multi reservoir operation optimization problem. Generally, different approaches can be proposed to improve the computational efficiency such as improving the mechanism of classical algorithms or proposing new and effective algorithms. It is worth noting that, although meta heuristic algorithms have been extensively used in the field of finding optimal reservoir operation due to their ability, however, their application to multi-reservoir system raises a number of challenges. The high dimensionality of the decision variables contributes a lot to these application challenges such as problem search space size, computational efficiency and so on. Therefore, this research focuses on the new research field for researcher to propose new effective methods for solving more complex multi-reservoir operation optimization problem.

As mentioned above, the non-linearity and the high dimensionality of the multi-reservoir systems lead to big challenges for this problem means the requirement of the using new heuristic algorithms or reducing dimensionality by proposing effective approaches. Therefore, a family of constrained versions for new meta heuristic algorithm, means gravitational search algorithm (GSA), is proposed here to solve multi-reservoir operation optimization problems. These algorithms are extension of the algorithms proposed by Moeini et al. (2017) for single reservoir operation optimization problem. Therefore, two constrained versions of the GSA are developed and used here to solve this complex optimization problem using the concept already used by Moeini and Afshar (2013) and Afshar (2013) using ACOA and PSO algorithm, respectively. In the first version, named partially constrained gravitational search algorithm (PCGSA), the constraints of the problem are partially satisfied. In other words, a feasible search space is constructed for each agent to simultaneously satisfy both water release and storage volume constraints. This algorithm is very successful for problem constraints satisfaction except for very rare cases. Therefore, another algorithm, named fully constrained gravitational search algorithm (FCGSA), is also proposed here. In the FCGSA, all the constraints of the problem are implicitly satisfied by providing a search space for each agent that contains only feasible solution. For this, the water storage volume bounds of the reservoirs are modified prior to the main search such that infeasible solutions cannot constructed. The FCGSA leads to smaller search space for each agent and therefore it is very useful when it is applied to solve large scale multi-reservoir operation optimization problem. The both constrained GSAs are formulated here for both possible variables of the problem means considering water release or storage volumes as the decision variables of the problem in which they are denoted by suffix $I$ and $I I$, respectively. The proposed algorithms are used here to solve the well-known four and ten reservoir operation optimization problems and the results are presented and compared with those of original form of the GSA and any available results in the literature. The results indicate the superiority of the proposed algorithm and especially FCGSA over existing methods to optimally solve large scale multi-reservoir operation optimization problem. This fact is highlighted in the section "Numerical experiments and results" when proposed algorithms are used to solve two benchmark test examples.

\section{Multi-Reservoir Operation Optimization Problem}

Nowadays, there are more than 45,000 large dams in the world in which they have been constructed to manage scarce water resources and mitigate devastating floods and droughts (Hınçal et al., 2011). Generally, dames control the surface runoff effectively due to seasonal variation demands. Therefore, a small improvement in the operating policies of a reservoir can lead to large benefits for many users. For this purpose, a reservoir operation problem can be considered as a decision-making problem. Solving this problem specifies how water is managed throughout the multi-reservoir system. Optimal operating policy serves to reach maximum benefit from the multi-reservoir system satisfying problem constraints. However, finding optimal operation policy for multi-reservoir system is a complex problem.

This problem involves many decision variables, constraints and multiple objectives in which they are naturally highly nonlinear and non-convex. Therefore, multi-reservoir operation problem can be properly solved using meta heuristic algorithms. Generally, a multi-reservoir system contains both parallel and series dam connections. In this system the outflow of up-stream reservoirs serves as the inflow of downstream reservoirs and 
therefore this condition adds the problem complexity.

Multi-reservoir operation optimization problem is characterized by various goals and constraints. Here, the goal of the problem is to maximize benefits from the multi-reservoir system over the operation time period that can be formulated as follows:

$F=\sum_{k=1}^{K} \sum_{t=1}^{T} b^{k}(t) \times r^{k}(t)$

where $F=$ the benefit (objective) function; $K=$ the total number of reservoirs; $T=$ the total number of operation time periods; $b^{k}(t)=$ the benefit function of reservoir $k$ at operation time period $t$; and $r^{k}(t)=$ the release from reservoir $k$ at operation time period $t$.

Generally, this problem has some fundamental constraints. For example, upper and lower bounds for releases and storages over each operating time period $t$ should be considered. Another constraint of the problem is continuity equation in which it should be satisfied throughout the whole system. These constraints can be defined as follows:

$S^{k}(t+1)=S^{k}(t)+I^{k}(t)-r^{k}(t)$

$S_{\min }^{k} \leq S^{k}(t) \leq S_{\max }^{k}$

$r_{\min }^{k} \leq r^{k}(t) \leq r_{\max }^{k}$

where $S^{k}(t)=$ the storage at operation time period $t$ of reservoir $k ; I^{k}(t)=$ the inflows at operation time period $t$ to reservoir $k$; $r^{k}(t)=$ the release at operation time period $t$ from reservoir $k$; $S_{\min }^{k}=$ the minimum storage of reservoir $k ; S_{\max }^{k}=$ the maximum storage of reservoir $k ; r_{\min }^{k}=$ the minimum release from reservoir $k$; and $r_{\max }^{k}=$ the maximum release from reservoir $k$.

\section{Proposed Methods to Solve Multi-Reservoir Operation Optimization Problem}

In this paper, two constrained versions of GSA are proposed to solve multi-reservoir operation optimization problem. In addition, standard form of GSA is also used here to solve the problem for comparison purpose. It is worth noting that, at first, Rashedi et al. (2009) proposed GSA to solve some benchmark mathematical function optimization problems. This algorithm was fully described in Rashedi's paper and therefore its theory is not presented here. Here, GSA is used and improved to solve multi-reservoir operation optimization problem. Basically, two different set of decision variables of water release or storage volumes can be taken for reservoir operation problem. Therefore, in this paper, two formulations are proposed for each proposed algorithm denoted by suffix $I$ and $I I$ considering water releases or storage volumes at each operation time period as decision variable of the problem, respectively. Proposed methods are briefly described as follows.

\subsection{Unconstrained GSA}

In the unconstrained GSA (UGSA), the standard and usual form of the GSA is used to solve reservoir operation problem. Two formulations are also proposed here for unconstrained GSA in which they are named UGSA $I$ and $\mathrm{UGSA}_{I I}$ considering water releases or storage volumes at each operation time period as decision variable of the problem, respectively. Here an assumption is considered that the initial storage volume of all reservoirs is known

In this algorithm, each operation time period of each reservoir is considered as each dimension of the trial agent leading to a total number of $K \times T$ dimensions and therefore a mapping of the type $i(i=\operatorname{Map}(k, t))$ is assumed for graphical representtation of each dimension.

Here, the value of each agent dimension presents the water release from reservoir/end of water storage volume at each operation time period for $\mathrm{UGSA}_{I} / \mathrm{UGSA}_{I I}$ which is created in the range $\left[r_{\min }^{k}, r_{\text {max }}^{k}\right] /\left[S_{\min }^{k}, S_{\max }^{k}\right]$ and therefore the agent position can be defined. By defining all agent positions using proposed mechanism, the agent positions are updated based on the GSA methodology. This mechanism is continued until the stop criteria are reached. It is worth noting that, based on this mechanism, the water release from reservoir/water storage volume at each operation time period constraint is easily satisfied using $\mathrm{UGSA}_{I} / \mathrm{UGSA}_{I I}$. In addition, in this proposed algorithm, the agent positions are updated independently. In other words, proposed mapping can be arbitrary and therefore the $i^{\text {th }}$ dimension of each agent can be arbitrarily associated to each operation time period of each reservoir ( $t^{\text {th }}$ operation time period of $k^{\text {th }}$ reservoir).

The graphical representation (search space) of the problem defined for the application of UGSAs is shown in Figure 1. Here, $d_{i}$ represents the $i^{\text {th }}$ dimension of the trial agent $(i=1, \ldots, K \times T)$, the horizontal small lines represent the agent position bounds (water release/end of storage volumes), bold horizontal small lines represent obtained values for each agent dimension and solid lines represent a trial solution created by UGSAs.

It should be noted that UGSAs may create infeasible solutions. Therefore, here, to discourage the agents to select water releases/storage volumes, which may constitute an infeasible solution, a lower benefit is associated to the infeasible solutions using penalty method:

$$
\begin{aligned}
& F_{p}= \begin{cases}F-\alpha_{p} \times \sum_{k=1}^{K} \sum_{t=1}^{T}\left(C S V_{s}^{k}(t)+C S V_{r}^{k}(t)\right) & \text { if } F_{p} \geq 0.0 \\
0 & \text { otherwise }\end{cases} \\
& C S V_{r}^{k}(t)=\left(1-\frac{r^{k}(t)}{r_{\min }^{k}}\right)+\left(\frac{r^{k}(t)}{r_{\max }^{k}}-1\right) \\
& C S V_{s}^{k}(t)=\left(1-\frac{S^{k}(t)}{S_{\min }^{k}}\right)+\left(\frac{S^{k}(t)}{S_{\max }^{k}}-1\right)
\end{aligned}
$$

where $F_{p}=$ the penalized objective function; $F=$ the original objective function (Equation $(1)) ; C S V_{s}^{k}(t)=$ the water storage volume constraint violation at operation time period $t$ of the reser- 
servoir $k ; C S V_{r}^{k}(t)=$ the water resale volume constraint violation at operation time period $t$ of the reservoir $k$ and $\alpha_{p}=$ the penalty constant which is obtained via a trial and error process. It should be noted that only the positive values of the term in the parenthesis of $C S V_{s}^{k}(t)$ and $C S V_{r}^{k}(t)$ are used for constraints violations calculation because of the reason discussed ahead. The negative or zero value of each term in the parenthesis means that the corresponding constraint is satisfied and therefore it is not used for calculation of constraints violations.

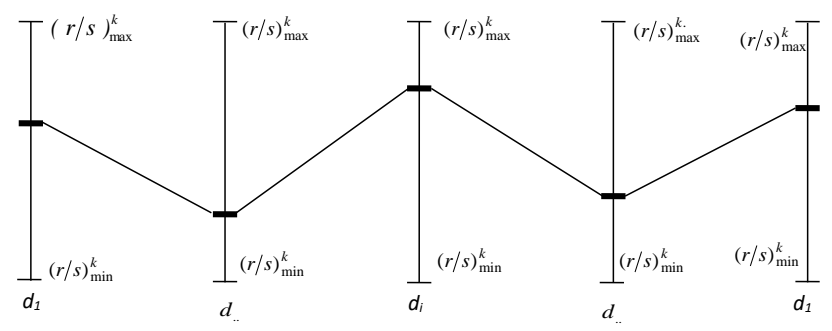

Figure 1. Search space of UGSA considering release/storage volume as decision variable for reservoir $k$.

\subsection{Partially Constrained GSA (PCGSA)}

Here, the GSA is equipped with an effective mechanism to solve optimization problems with constraints of sequential nature such as reservoir operation optimization problem proposing two constrained versions of GSA named partially and fully constrained GSA (PCGSA \& FCGSA). Based on this mechanism, a component by component approach is used to create a trail solution incrementally and therefore each dimension of the agent is updated in turn using same dimension information. Among this process, the explicit nature of reservoir operation problem constraints can be easily enforced limiting the agent positions. Therefore, each agent is forced to move to the feasible search space. This mechanism leads to smaller search space and therefore better solution especially for solving large scale optimization problem. In addition, the limitations of penalty method are extremely reduced. This mechanism equipped with GSA has already been used to solve single reservoir operation optimization problem by Moeini et al. (2017) which is now extended to solve multi-reservoir operation. It should be noted that the release (storage) volume constraints of the downstream reservoirs are affected not only by their operation but also by the upstream reservoirs' operation and therefore the constraints of the multi-reservoir operation optimization problem are more complex than the single reservoir operation problem. Here, constrained GSA is developed to satisfy the problem constraints as much as possible in order to overcome this complexity.

Here, in the PCGSA, the local operation of each reservoir is determined such that the corresponding constraints are satisfied. Two formulations are also proposed for PCGSA in which they are named PCGSA $_{I}$ and PCGSA $_{I I}$ considering water releases or storage volumes at each operation time period as decision variable of the problem, respectively. An assumption is considered here that the initial storage volumes of all reservoirs are known. Here, an arbitrary dimension of an agent ( $i$ dimension, corresponding to operation time period $t$ of the $k^{\text {th }}$ reservoir) with a known value for the corresponding water release/storage volume is considered. In order to calculate a new set of bounds for water release/storage volume of the $(i+1)^{\text {th }}$ dimension (corresponding to the operation time period $t+1$ of reservoir $k$ ), in $\mathrm{PCGSA}_{I} / \mathrm{PCGSA}_{I I}$ respectively, the continuity equation can be used such that the remaining constraints are fully satisfied by the resulting values. These new bounds are used to obtain $(i+$ $1)^{\text {th }}$ dimension of an agent containing only feasible position. In other words, the $(i+1)^{\text {th }}$ dimension of the agent is obtained by calculating new bound for water release/storage volumes and selecting the position from this new bound. Proposed algorithms can be briefly described as follows.

In PCGSA , a known value for $S^{k}(t)$ is assumed and the continuity equation can be used to substitute $S^{k}(t+1)$ into storage volume constraint rewritten for operation time period $t+1$. Therefore, the following constraint can be obtained for the water release from the reservoir $k$ at operation time period $t$ :

$$
S^{k}(t)+I^{k}(t)-S_{\max }^{k} \leq r^{k}(t) \leq S^{k}(t)+I^{k}(t)-S_{\min }^{k}
$$

This equation should be combined with the original water release volume constraint and therefore the following constraint can be obtained for water release from the reservoir $k$ at operation time period $t$ in which the resulting $S^{k}(t+1)$ is feasible:

$$
\begin{aligned}
\operatorname{Max}\left(r_{\min }^{k}, S^{k}(t)+I^{k}(t)-S_{\max }^{k}\right) \leq r^{k}(t) \\
\leq \operatorname{Min}\left(r_{\max }^{k}, S^{k}(t)+I^{k}(t)-S_{\min }^{k}\right)
\end{aligned}
$$

However, in PCGSA $I I$, a known value for $S^{k}(t)$ is assumed and the continuity equation can be used to substitute $r^{k}(t)$ into water release constraint rewritten for operation time period $t$. Therefore, the following constraint can be obtained for the water storage volume of the reservoir $k$ at end of operation time period $t$ (start of operation time period $t+1)$ :

$S^{k}(t)+I^{k}(t)-r_{\max }^{k} \leq S^{k}(t+1) \leq S^{k}(t)+I^{k}(t)-r_{\min }^{k}$

This equation should be combined with the original storage volume constraint and therefore the following constraint can be obtained for water storage volume of the reservoir $k$ at end of operation time period $t$ (start of operation time period $t$ $+1)$ in which the resulting $S^{k}(t+1)$ is feasible:

$$
\begin{array}{r}
\operatorname{Max}\left(S_{\min }^{k}, S^{k}(t)+I^{k}(t)-r_{\max }^{k}\right) \leq S^{k}(t+1) \\
\leq \operatorname{Min}\left(S_{\max }^{k}, S^{k}(t)+I^{k}(t)-r_{\min }^{k}\right)
\end{array}
$$

This procedure is repeated in turn for the next decision point until a complete solution is created. It should be noted that the created solutions automatically satisfy water release and storage volume constraints except for some rare cases. The graphical representation (search space) of the problem defined for the application of PCGSAs is shown in Figure 2. Here, $d_{i}$ represents the $i^{\text {th }}$ dimension of the trial agent $(i=1, \ldots, K \times T)$, the horizontal 
small lines represent the agent position original bounds (water release/end of storage volumes), the triangles represent the new agent position bounds (water release/end of storage volumes) calculated using Equation (7) / Euqation (9), the bold horizontal small lines represent obtained values for each agent dimension and solid lines represent a trial solution is created by PCGSAs. Comparison of the Figures 1 and 2 indicates that the obtained search space is feasible in most cases and therefore it is much smaller than the original search space. Therefore, it is expected that the proposed new algorithm (PCGSA) will perform better than the original form of the algorithm (UGSA).

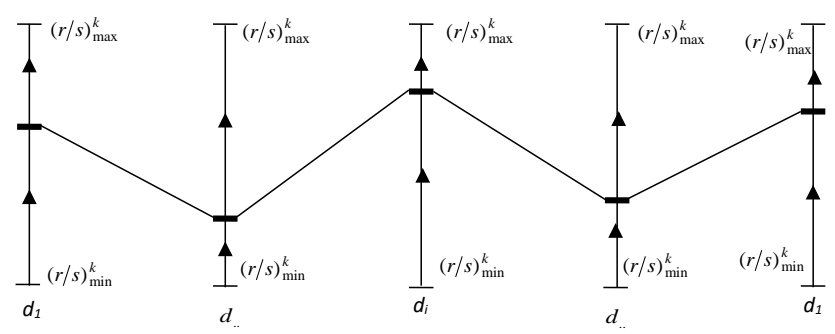

Figure 2. Search space of PCGSA considering release/storage volume as decision variable for reservoir $k$.

\subsection{Fully Constrained GSA (FCGSA)}

It is worth noting that sometimes PCGSA fails to produce a feasible solution. Generally, occurring this condition depends on the created solution and more importantly the magnitude of the $I^{k}(t)$. In other words, this condition is occur when the new range defined for water release/storage volumes using Equation (7) / Equation (9) is empty. Here, this problem is resolved by present-ing the agent with a single option, means upper or lower bound of the water release or storage volumes for $\mathrm{PCGSA}_{I}$ or PCGSA PI $_{I}$, to choose a value which will constitute an infeasible solution. This mechanism is schematically presented in Figure 3. This problem can be resolved here proposing a simple and effective modification for PCGSA. This modification leads to an algorithm named fully constrained GSA (FCGSA) which will never produce an infeasible operation policy. In the FCGSA, infeasible regions of the problem are theoretically estimated and removed from the original search space before starting the process so that agents are not allowed to create infeasible solutions at all. In other words, a new manner is used to modify the bounds of the storage volume constraint before applying the concept of PCGSA. In this new manner, the operation time periods are swept in reverse order and a set of new bounds are calculated for storage volumes constraint at the beginning of the operation time period. Here, two formulations are also proposed for FCGSA in which they are named FCGSA $_{I}$ and FCGSA $I I$ considering water releases or storage volumes at each operation time period as decision variable of the problem, respectively.

In FCGSA, by starting from the last operation time period and considering the storage volume constraint for reservoir $k$ at a period $t+1$ as follows:

$S_{\min }^{k} \leq S^{k}(t+1) \leq S_{\max }^{k}$
The $S^{k}(t+1)$ is substituted from continuity equation into Equation (10) leading to the following new constraint for the storage volume at the beginning of the operation time period $t$, $S^{k}(t)$, as follows:

$r^{k}(t)-I^{k}(t)+S_{\min }^{k} \leq S^{k}(t) \leq r^{k}(t)-I^{k}(t)+S_{\max }^{k}$

This constraint should be valid for any value of water release in the defined range $\left[r_{\min }^{k}, r_{\max }^{k}\right]$ and therefore the following equation should be considered:

$r_{\min }^{k}-I^{k}(t)+S_{\min }^{k} \leq S^{k}(t) \leq r_{\max }^{k}-I^{k}(t)+S_{\max }^{k}$

This equation combines with the original constraint of water storage volumes leading to the new constraint for the storage volume at the beginning of the period as follows:

$\bar{S}_{\min }^{k}(t) \leq S^{k}(t) \leq \bar{S}_{\max }^{k}(t)$

with,

$\bar{S}_{\min }^{k}(t)=\operatorname{Max}\left(S_{\min }^{k}, r_{\min }^{k}-I^{k}(t)+S_{\min }^{k}\right)$

$\bar{S}_{\max }^{k}(t)=\operatorname{Min}\left(S_{\max }^{k}, r_{\max }^{k}-I^{k}(t)+S_{\max }^{k}\right)$

where, $\bar{S}_{\min }^{k}, \bar{S}_{\max }^{k}=$ the new bounds calculated for the water storage volume of reservoir $k$ at operation time period $t$. It should be noted that these calculated bounds are different from the originnal water storage bounds and they are used in Equation (3) instead of original $S_{\min }^{k}$ and $S_{\max }^{k}$. These bounds are calculated only once at the beginning of the calculation and they are different from one period to another one. These new bounds are then used in the search process of PCGSA defined before leading an algorithm which will not create any infeasible solution during the search process.

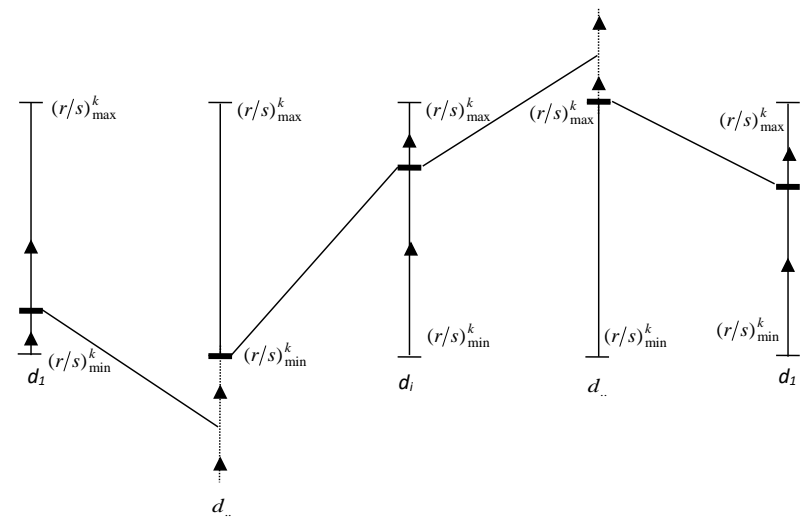

Figure 3. Schematically explanation of occurring invalid infeasible solution for PCGSA considering release/storage volume as decision variable for reservoir $k$.

The graphical representation (search space) of the problem defined for the application of FCGSA $I I$ is shown in Figure 4. Here, $d_{i}$ represents the $i^{\text {th }}$ dimension of the trial agent $(i=1, \ldots$, $K \times T)$, the horizontal small lines represent the agent position 
original bounds (water release/end of storage volumes), the squares represent new bounds calculated for water storage volume at each operation time period using Equations (13), the triangles represent the new agent position bounds (end of storage volumes) calculated using Equation (9), the bold horizontal small lines represent obtained values for each agent dimension and solid lines represent a trial solution created by FCGSA $I I$. It should be noted that this procedure is also used when the water release volumes are taken as decision variables of the problem proposing $\mathrm{FCGSA}_{I}$. In addition, the modification of storage volumes bounds (Equation (13)) cannot be directly used for downstream reservoirs since the values of inflow to these reservoirs are not known before the operation policies of all upstream reservoirs are calculated. This face should be attended for considering the sequence of the dimensions applied for defining the multi-reservoir operation search space. Comparison of the Figures 1,2 , and 4 indicates that the obtained search space is always feasible and it is much smaller than the original search space. Therefore, it is expected that the proposed FCGSA will perform better than proposed PCGSA and especially the original UGSA.

\section{Numerical Experiments and Results}

In order to verify the efficiency of the proposed algorithms, here, the well-known four and ten reservoir operation problems are solved using proposed algorithms. Chow and Cortes-Rivera (1974), at first, introduced the hypothetical four reservoir system as shown in Figure 5. There are inflows to the only first and second reservoirs of four reservoir system at all operation time periods. The initial and target storages at the end of the operation time period are considered for all reservoirs. The values for the water storage and release bounds are presented as follows: $S_{\min }^{1}$, $S_{\min }^{2}, S_{\min }^{3}$, and $S_{\min }^{4}=1 ; r_{\min }^{1}, r_{\min }^{2}, r_{\min }^{3}$, and $r_{\min }^{4}=0.005 ; r_{\max }^{1}=$ $4, r_{\max }^{2}$, and $r_{\max }^{3}=4.5 ; r_{\max }^{4}=8$. Other parameters such as initial storages, $b^{k}(t), S_{\max }^{k}$, and $I^{k}(t)$ are presented in Table 1 . In addition, Murray and Yakowitz (1979), at first, introduced the hypothetical ten- reservoir system as shown in Figure 6. There are inflows to the only upstream reservoirs of ten reservoir system (reservoir 1, 2, 3, 5, 6 and 8) in all operation time periods. The initial and target storages at the end of the operation time period are considered for all reservoirs. The values for water storage and release bounds are presented as follows:

$s_{\text {min }}^{1}=s_{\text {min }}^{2}=s_{\text {min }}^{4}=s_{\text {min }}^{5}=s_{\text {min }}^{6}=s_{\text {min }}^{7}=s_{\text {min }}^{8}=s_{\text {min }}^{10}=1$,

$s_{\min }^{3}=0.3, s_{\min }^{9}=0.5$,

$r_{\text {min }}^{1}=r_{\text {min }}^{2}=r_{\text {min }}^{3}=r_{\text {min }}^{4}=0.005, r_{\text {min }}^{5}=r_{\text {min }}^{6}=0.006$,

$r_{\text {min }}^{7}=r_{\text {min }}^{10}=0.01, r_{\text {min }}^{8}=r_{\text {min }}^{9}=0.008$,

$r_{\text {max }}^{1}=4, r_{\text {max }}^{2}=4.5, r_{\text {max }}^{3}=2.12, r_{\text {max }}^{4}=7, r_{\text {max }}^{5}=6.43$,

$r_{\max }^{6}=4.21, r_{\max }^{7}=17.1, r_{\max }^{8}=3.1, r_{\max }^{9}=4.2, r_{\max }^{10}=18.9$.

Other parameters such as initial storages, $b^{k}(t), S_{\max }^{k}$, and $I^{k}(t)$ are presented in Table 2.
It should be noted that the search space of four and ten reservoir operation problems can be defined using the detail of these two problems and corresponding equations for all proposed algorithms (such as UGSA, PCGSA, FCGSA). Here, only the graph (search space) of FCGSA $_{I I}$ is presented for first reservoir (reservoir 1) of four reservoir operation problem in Figure 7. The graphs (search spaces) of all reservoirs of both four and ten reservoir operation problems using both proposed formulations ( $I$ and $I I$ ) of UGSA, PCGSA, FCGSA can be easily defined such as Figure 7; however, these figures are not presented here to avoid lengthy paper.

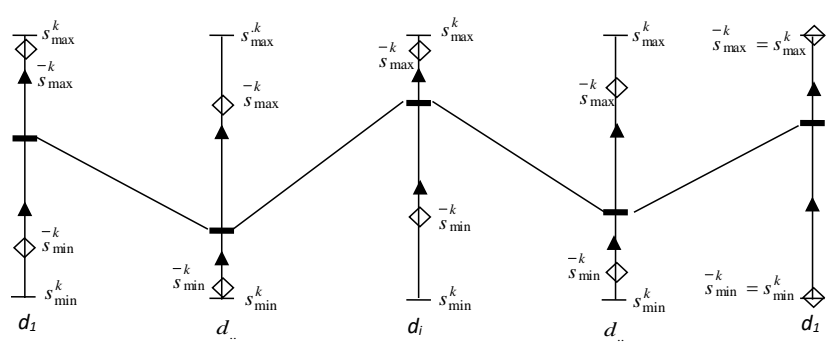

Figure 4. Search space of FCGSA considering storage volume as decision variable for reservoir $k$.

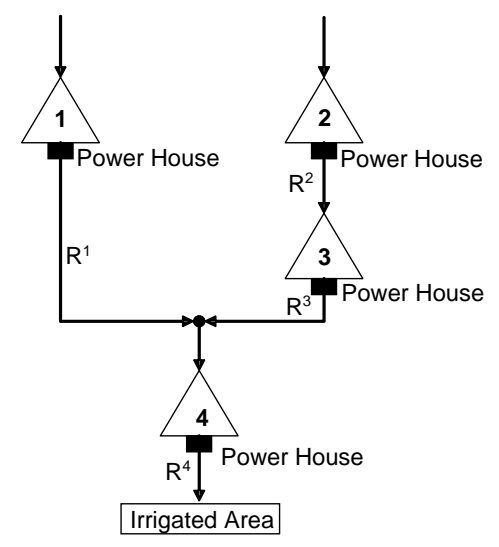

Figure 5. Four-reservoir system.

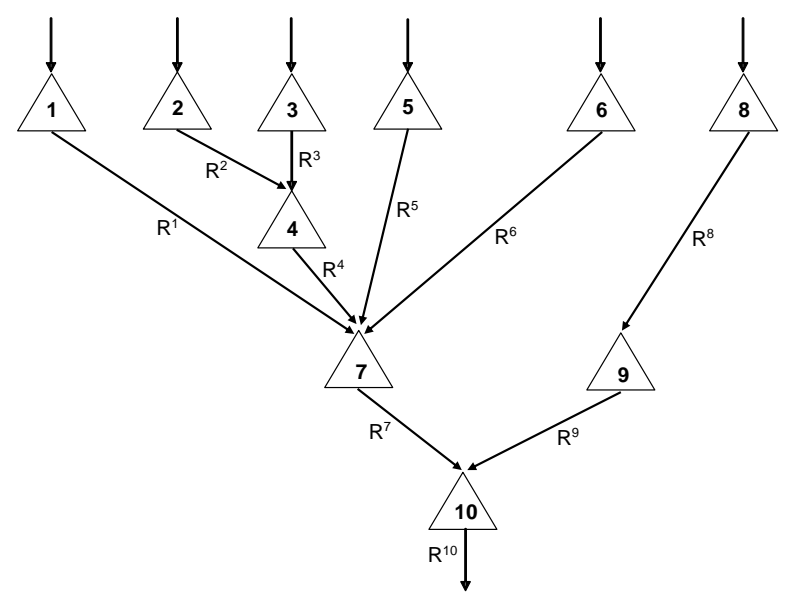

Figure 6. Ten-reservoir system. 


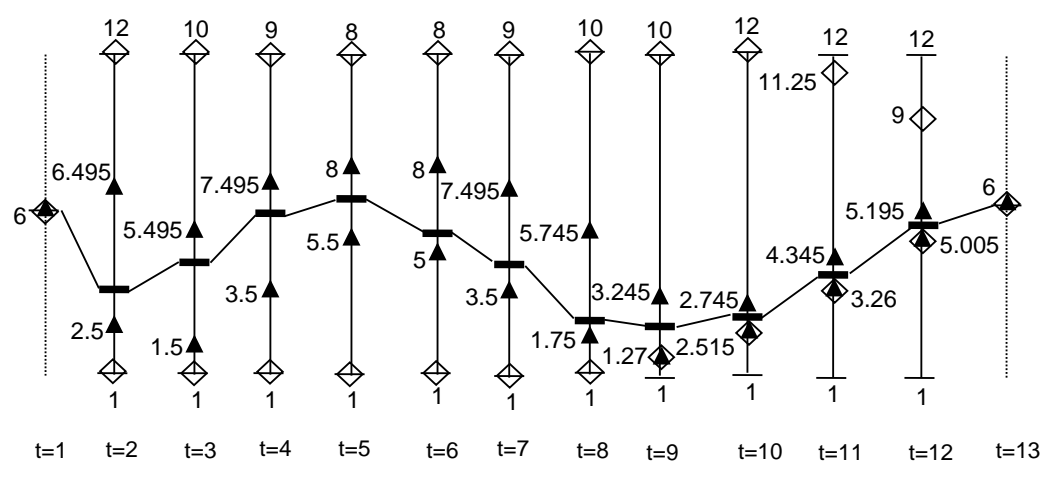

Figure 7. Graph (search space) of $\mathrm{FCGSA}_{I I}$ for reservoir one of four-reservoir operation problem.

Table 1. Parameter Values of Reservoirs at Operation Time Periods for Four-Reservoir System

\begin{tabular}{|c|c|c|c|c|c|c|c|c|c|c|c|c|c|}
\hline \multirow{2}{*}{ Parameters values } & \multirow{2}{*}{ Reservoir } & \multicolumn{12}{|c|}{ Operation time period } \\
\hline & & 1 & 2 & 3 & 4 & 5 & 6 & 7 & 8 & 9 & 10 & 11 & 12 \\
\hline \multirow{4}{*}{$\begin{array}{l}\text { Maximum water } \\
\text { storage }\end{array}$} & 1 & 6 & 12 & 10 & 9 & 8 & 8 & 9 & 10 & 10 & 12 & 12 & 12 \\
\hline & 2 & 6 & 15 & 15 & 12 & 12 & 12 & 15 & 17 & 18 & 18 & 18 & 15 \\
\hline & 3 & 6 & 8 & 8 & 8 & 8 & 8 & 8 & 8 & 8 & 8 & 8 & 8 \\
\hline & 4 & 8 & 15 & 15 & 15 & 15 & 15 & 15 & 15 & 15 & 15 & 15 & 15 \\
\hline \multirow{4}{*}{ Benefit function } & 1 & 1.1 & 1 & 1 & 1.2 & 1.8 & 2.5 & 2.2 & 2 & 1.8 & 2.2 & 1.8 & 1.4 \\
\hline & 2 & 1.4 & 1.1 & 1 & 1 & 1.2 & 1.8 & 2.5 & 2.2 & 2 & 1.8 & 2.2 & 1.8 \\
\hline & 3 & 1 & 1 & 1.2 & 1.8 & 2.5 & 2.2 & 2 & 1.8 & 2.2 & 1.8 & 1.4 & 1.1 \\
\hline & 4 & 2.6 & 2.9 & 3.6 & 4.4 & 4.2 & 4 & 3.8 & 4.1 & 3.6 & 3.1 & 2.7 & 2.5 \\
\hline \multirow{4}{*}{ Inflow } & 1 & 0.5 & 1 & 2 & 3 & 3.5 & 2.5 & 2 & 1.25 & 1.25 & 0.75 & 1.75 & 1 \\
\hline & 2 & 0.4 & 0.7 & 2 & 2 & 4 & 3.5 & 3 & 2.5 & 1.3 & 1.2 & 1 & 0.7 \\
\hline & 3 & 0 & 0 & 0 & 0 & 0 & 0 & 0 & 0 & 0 & 0 & 0 & 0 \\
\hline & 4 & 0 & 0 & 0 & 0 & 0 & 0 & 0 & 0 & 0 & 0 & 0 & 0 \\
\hline
\end{tabular}

A set of preliminary runs are done here to find the proper values of GSA parameters as shown in Table 3 for four and ten reservoir system operation problems. However, details of sensitivity analysis for finding best values of all parameters are not presented here to avoid lengthy paper. Table 4 shows the results of 10 runs carried out for the four and ten reservoir system operation problems using first $(I)$ and second (II) formulations of all proposed algorithms. It is clearly seen that all the results, including minimum, maximum and average objective function values, scaled standard deviation obtained with both proposed formulations of FCGSA for four and ten reservoir system operation problems are better than those produced by UGSA and PCGSA. The superiority of the results obtained by the FCGSA is more evident for the ten-reservoir system illustrating the efficiency of the FCGSA to solve large scale optimization problems due to special characteristics of FCGSA in which all the obtained solutions of FCGAS are always feasible leading to smaller search space size. In addition, the scattering of the obtained solutions decreases as one move from UGSA to PCGSA and from PCGSA to FCGSA. It is worth noting that the performance of constrained versions of GSA with water release volumes are taken as decision variables (formulation $I$ ) is better than those when water storage volumes are taken as decision variables (formulation $I I$ ) which can be attributed to the fact that the search space size of the problem is greater in second formulation.

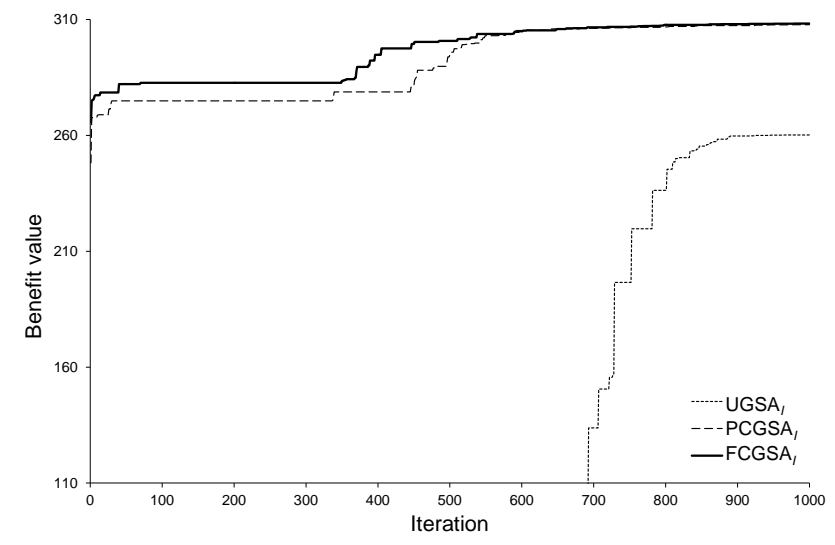

Figure 8. Maximum benefit values versus iterations for fourreservoir system operation problem using $\mathrm{UGSA}_{I}, \mathrm{PCGSA}_{I}$ and FCGSA $_{I}$.

Here, two convergence curves are presented as Figures 8 and 9 to indicate this fact that the search space created by FCGSA is totally feasible. These figures present maximum 
benefit value obtained for the four and ten reservoir system operation problems, respectively, when water releases are taken as decision variable (formulation $I$ ). It is clearly seen from these figures that the initial population of FCGSA has maximum benefit value way over that of PCGSA and UGSA due to the fact that all the solutions created by FCGSA are always feasible. Finally, Figures 10 and 11 are presented to indicate better performance of first formulation $(I)$ than second ones $(I I)$ due to the reason of smaller search space size (Moeini and Afshar, 2009; Afshar, 2013). This can be easily seen by a comparison between allowable range of water release volumes considering as decision variable in formulation $I$ and water storage volumes considering as decision variable in formulation II presented in this section and Tables 1 and 2. Based on these values, the space size of formulation II is more than twice or triples of formulation $I$. In other words, the allowable range of water release volumes are smaller than water storage volumes range leading to smaller search space size and therefore better solution with minor commotional cost. These figures present maximum benefit value obtained for the four and ten reservoir system operation problems, respectively, using first and second formulations of FCGSA (FCGSA $I$ and FCGSA FC. $_{I I}$.

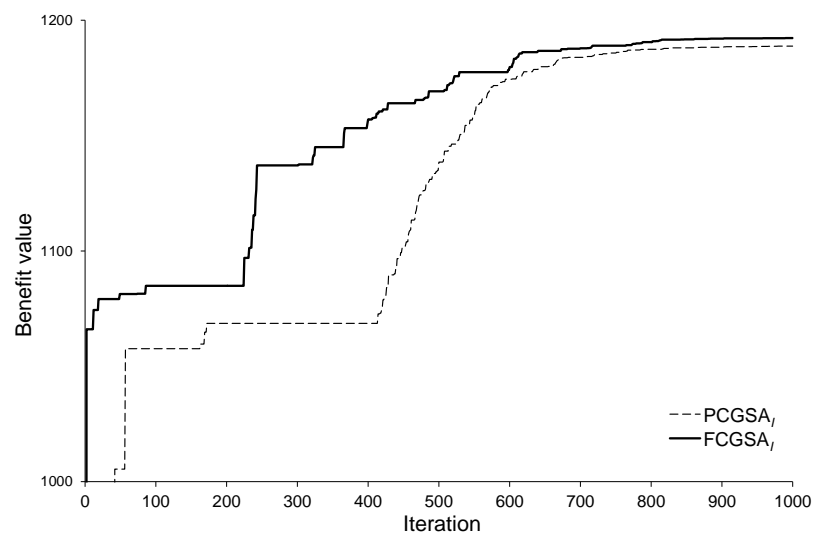

Figure 9. Maximum benefit values versus iterations for tenreservoir system operation problem using $\mathrm{UGSA}_{I}, \mathrm{PCGSA}_{I}$ and FCGSA .

Table 2. Parameter Values of Reservoirs at Operation Time Periods for Ten-Reservoir System

\begin{tabular}{|c|c|c|c|c|c|c|c|c|c|c|c|c|c|}
\hline \multirow{2}{*}{ Parameters values } & \multirow{2}{*}{ Reservoir } & \multicolumn{12}{|c|}{ Operation time period } \\
\hline & & 1 & 2 & 3 & 4 & 5 & 6 & 7 & 8 & 9 & 10 & 11 & 12 \\
\hline \multirow{10}{*}{ Maximum water storage } & 1 & 6 & 12 & 12 & 10 & 9 & 8 & 8 & 9 & 10 & 10 & 12 & 12 \\
\hline & 2 & 6 & 17 & 15 & 15 & 15 & 12 & 12 & 15 & 17 & 18 & 18 & 18 \\
\hline & 3 & 3 & 6 & 6 & 6 & 6 & 6 & 6 & 6 & 6 & 6 & 6 & 6 \\
\hline & 4 & 8 & 19 & 18 & 17 & 16 & 15 & 14 & 14 & 15 & 16 & 17 & 18 \\
\hline & 5 & 8 & 19.1 & 18.1 & 17.1 & 16.1 & 15.2 & 14.1 & 14.2 & 15.3 & 16.1 & 17.2 & 18.3 \\
\hline & 6 & 7 & 14 & 13 & 12 & 11 & 10 & 8.5 & 9.6 & 10.7 & 11.8 & 12.9 & 14 \\
\hline & 7 & 15 & 30 & 30 & 30 & 30 & 30 & 30 & 30 & 30 & 30 & 30 & 30 \\
\hline & 8 & 6 & 13.16 & 12.23 & 11.37 & 10.2 & 9.6 & 9 & 9.6 & 10.2 & 11.58 & 12.96 & 1318 \\
\hline & 9 & 5 & 7.9 & 7.3 & 6.8 & 6.4 & 6.2 & 6.1 & 6.4 & 6.7 & 7 & 7.4 & 8 \\
\hline & 10 & 15 & 30 & 30 & 30 & 30 & 30 & 30 & 30 & 30 & 30 & 30 & 30 \\
\hline \multirow{10}{*}{ Benefit function } & 1 & 1.1 & 1 & 1 & 1.2 & 1.8 & 2.5 & 2.2 & 2 & 1.8 & 2.2 & 1.8 & 1.4 \\
\hline & 2 & 1.4 & 1.1 & 1 & 1 & 1.2 & 1.8 & 2.5 & 2.2 & 2 & 1.8 & 2.2 & 1.8 \\
\hline & 3 & 1 & 1 & 1.2 & 1.8 & 2.5 & 2.2 & 2 & 1.8 & 2.2 & 1.8 & 1.4 & 1.1 \\
\hline & 4 & 1.1 & 1 & 1 & 1.2 & 1.8 & 2.5 & 2.2 & 2 & 1.8 & 2.2 & 1.8 & 1.4 \\
\hline & 5 & 1 & 1.1 & 1.2 & 1.3 & 1.4 & 1.5 & 1.67 & 1.56 & 1.45 & 1.34 & 1.25 & 1.14 \\
\hline & 6 & 1.4 & 1.1 & 1 & 1 & 1.2 & 1.8 & 2.5 & 2.2 & 2 & 1.8 & 2.2 & 1.8 \\
\hline & 7 & 2.7 & 2.9 & 3.6 & 4.4 & 4.2 & 4 & 3.8 & 4.1 & 3.6 & 3.1 & 2.7 & 2.5 \\
\hline & 8 & 1 & 1.1 & 1.2 & 1.3 & 1.4 & 1.5 & 1.67 & 1.56 & 1.45 & 1.34 & 1.25 & 1.14 \\
\hline & 9 & 1 & 1 & 1.2 & 1.8 & 2.5 & 2.2 & 2 & 1.8 & 2.2 & 1.8 & 1.4 & 1.1 \\
\hline & 10 & 2.7 & 3 & 2.8 & 3.2 & 2.9 & 3.9 & 4 & 3.6 & 3.7 & 2.8 & 3.5 & 2.1 \\
\hline \multirow{10}{*}{ Inflow } & 1 & 0.5 & 1 & 2 & 3 & 3.5 & 2.5 & 2 & 1.25 & 1.25 & 0.75 & 1.75 & 1 \\
\hline & 2 & 0.4 & 0.7 & 2 & 2 & 4 & 3.5 & 3 & 2.5 & 1.3 & 1.2 & 1 & 0.7 \\
\hline & 3 & 0.8 & 0.8 & 0.8 & 0.8 & 0.8 & 0.8 & 0.8 & 0.8 & 0.8 & 0.8 & 0.8 & 0.8 \\
\hline & 4 & 0 & 0 & 0 & 0 & 0 & 0 & 0 & 0 & 0 & 0 & 0 & 0 \\
\hline & 5 & 1.5 & 2 & 2.5 & 2.5 & 3 & 3.5 & 3.5 & 3 & 2.5 & 2.5 & 2 & 1.5 \\
\hline & 6 & 0.32 & 0.81 & 1.53 & 2.16 & 2.31 & 4.32 & 4.81 & 2.24 & 1.63 & 1.91 & 0.8 & 0.46 \\
\hline & 7 & 0 & 0 & 0 & 0 & 0 & 0 & 0 & 0 & 0 & 0 & 0 & 0 \\
\hline & 8 & 0.71 & 0.83 & 1 & 1.25 & 1.67 & 2.5 & 2.8 & 1.87 & 1.45 & 1.2 & 0.93 & 0.81 \\
\hline & 9 & 0 & 0 & 0 & 0 & 0 & 0 & 0 & 0 & 0 & 0 & 0 & 0 \\
\hline & 10 & 0 & 0 & 0 & 0 & 0 & 0 & 0 & 0 & 0 & 0 & 0 & 0 \\
\hline
\end{tabular}


Table 3. Values of GSA Parameters for Four- and Ten-Reservoir Systems

\begin{tabular}{lllllll}
\hline Problem & Decision Variable & Iteration & Population & $\alpha$ & $G_{0}$ & $R_{\text {power }}$ \\
\hline \multirow{2}{*}{ Four-reservoir system } & Water release (I) & 1000 & 100 & 1 & 100 & 1 \\
& Water storage (II) & 1000 & 100 & 1 & 100 & 0.8 \\
& & & & & 300 & 1 \\
\multirow{2}{*}{ Ten-reservoir system } & Water release (I) & 1000 & 100 & 1 & 1 & 100 \\
\hline
\end{tabular}

Table 4. Obtained Results over 10 Runs for Four- and Ten-Reservoir Operation Problems using all Proposed Algorithms

\begin{tabular}{|c|c|c|c|c|c|c|c|c|}
\hline \multirow{2}{*}{ Problem } & \multirow{2}{*}{$\begin{array}{l}\text { Decision } \\
\text { Variable }\end{array}$} & \multirow[b]{2}{*}{ Algorithm } & \multicolumn{3}{|c|}{ Benefit values } & \multirow{2}{*}{$\begin{array}{l}\text { Scaled } \\
\text { standard } \\
\text { deviation }\end{array}$} & \multirow{2}{*}{$\begin{array}{l}\text { No. of runs with } \\
\text { final feasible } \\
\text { solution }\end{array}$} & \multirow{2}{*}{$\begin{array}{l}\text { Number of } \\
\text { function } \\
\text { evaluation }\end{array}$} \\
\hline & & & Maximum & Minimum & Average & & & \\
\hline \multirow{6}{*}{$\begin{array}{l}\text { Four- } \\
\text { reservoir } \\
\text { system }\end{array}$} & \multirow{3}{*}{$\begin{array}{l}\text { Water } \\
\text { release }\end{array}$} & $\mathrm{UGSA}_{I}$ & 260.216 & 254.188 & 256.329 & 0.0079 & 10 & 99800 \\
\hline & & $\mathrm{PCGSA}_{I}$ & 307.741 & 305.344 & 306.48 & 0.0024 & 10 & 98100 \\
\hline & & $\mathrm{FCGSA}_{I}$ & 308.238 & 307.322 & 307.744 & 0.0007 & 10 & 97900 \\
\hline & \multirow{3}{*}{$\begin{array}{l}\text { Water } \\
\text { storage }\end{array}$} & $\mathrm{UGSA}_{I I}$ & 301.360 & 297.558 & 300.215 & 0.0039 & 10 & 99100 \\
\hline & & $\mathrm{PCGSA}_{I I}$ & 306.910 & 303.065 & 304 & 0.0034 & 10 & 93700 \\
\hline & & $\mathrm{FCGSA}_{I I}$ & 307.735 & 306.646 & 307.264 & 0.0011 & 10 & 95100 \\
\hline \multirow{6}{*}{$\begin{array}{l}\text { Ten- } \\
\text { reservoir } \\
\text { system }\end{array}$} & \multirow{3}{*}{$\begin{array}{l}\text { Water } \\
\text { release }\end{array}$} & $\mathrm{UGSA}_{I}$ & infeasible & infeasible & infeasible & - & 0 & - \\
\hline & & $\mathrm{PCGSA}_{I}$ & 1188.782 & 1182.279 & 1185.829 & 0.002 & 10 & 99900 \\
\hline & & $\mathrm{FCGSA}_{I}$ & 1192.259 & 1191.357 & 1191.802 & 0.0002 & 10 & 99100 \\
\hline & \multirow{3}{*}{$\begin{array}{l}\text { Water } \\
\text { storage }\end{array}$} & $\mathrm{UGSA}_{I I}$ & 1162.09 & 1138.61 & 1152.72 & 0.0059 & 10 & 97600 \\
\hline & & $\mathrm{PCGSA}_{I I}$ & 1180.156 & 1151.635 & 1170.355 & 0.0039 & 10 & 91700 \\
\hline & & $\mathrm{FCGSA}_{I I}$ & 1190.659 & 1185.792 & 1188.086 & 0.0012 & 10 & 89900 \\
\hline
\end{tabular}

Table 5. Comparison the Results Obtained with Different Methods for Four- and Ten-Reservoir Operation Problem

\begin{tabular}{|c|c|c|c|c|c|c|c|}
\hline \multicolumn{8}{|c|}{ Four-reservoir system (methods, number of function evaluation) } \\
\hline \multirow{2}{*}{\multicolumn{2}{|c|}{$\begin{array}{l}\text { Constrained DDP } \\
\text { (Murray and Yakowitz, 1979) } \\
307.98\end{array}$}} & \multirow{2}{*}{\multicolumn{2}{|c|}{$\begin{array}{l}\text { Improved ACO with DR } \\
\text { (Jalali, 2005) } \\
307.976 \\
(6,000,000)\end{array}$}} & \multirow{2}{*}{\multicolumn{2}{|c|}{$\begin{array}{l}\text { MMAS } \\
\text { (Moeini, 2014) } \\
307.582 \\
(2,500,000)\end{array}$}} & \multirow{3}{*}{$\begin{array}{l}\text { FCPSO } \\
\text { (Afshar, 2013) } \\
308.4 \\
(200,000) \\
\end{array}$} & \multirow{2}{*}{$\begin{array}{l}\text { FCGSAI }_{\text {(present work) }} \\
308.238 \\
(97,900)\end{array}$} \\
\hline & & & & & & & \\
\hline \multicolumn{7}{|c|}{ Ten-reservoir system (methods, number of function evaluation) } & \\
\hline $\begin{array}{l}\text { Constrained DDP } \\
\text { (Murray and } \\
\text { Yakowitz, 1979) }\end{array}$ & $\begin{array}{l}\text { GA } \\
\text { (Wardlaw } \\
\text { and Sharif, } \\
\text { 1999) }\end{array}$ & $\begin{array}{l}\text { Improved } \\
\text { ACO } \\
\text { (Jalali, 2005) }\end{array}$ & $\begin{array}{l}\text { Improved } \\
\text { ACO with } \\
\text { DR } \\
\text { (Jalali, 2005) }\end{array}$ & $\begin{array}{l}\text { FCACOA } \\
\text { (Moeini and } \\
\text { Afshar, 2013) }\end{array}$ & $\begin{array}{l}\text { Multi colony } \\
\text { ACO (Jalali } \\
\text { et al., 2007) }\end{array}$ & $\begin{array}{l}\text { FCPSO } \\
\text { (Afshar, 2013) }\end{array}$ & $\begin{array}{l}\text { FCGSA }_{\text {I }} \\
\text { (present work) }\end{array}$ \\
\hline 1190.652 & $\begin{array}{l}1190.25 \\
(1,250,000)\end{array}$ & $\begin{array}{l}1153.64 \\
(6,000,000)\end{array}$ & $\begin{array}{l}1174.69 \\
(6,000,000)\end{array}$ & $\begin{array}{l}1190.26 \\
(1,500,000)\end{array}$ & $\begin{array}{l}1192.39 \\
(300,000)\end{array}$ & $\begin{array}{l}1194.05 \\
(200,000)\end{array}$ & $\begin{array}{l}1192.259 \\
(99,100)\end{array}$ \\
\hline
\end{tabular}

These problems have also been solved by other researchers proposing different methods. Table 5 compares the best results of four and ten reservoir system operation problems produced by the proposed FCGSA with some other available results and the computational effort (number of function evaluation) required by these methods. Comparison of the results shows that the results of first formulation of FCGSA $\left(\mathrm{FCGSA}_{I}\right)$ are improved $0.084,0.08$, and $0.21 \%$ in comparison with DDP, ACO with DR and MMAS methods, respectively, using less computational effort for solving four reservoir operation optimization problem. In addition, the computation effort of FCPSO was more

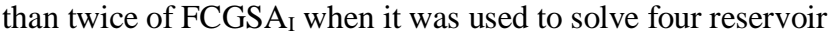
operation optimization problem. Furthermore, comparison of the results shows that the results of first formulation of FCGSA $\left(\right.$ FCGSA $\left._{I}\right)$ are improved $0.135,0.169,3.347,1.496$, and $0.168 \%$ in comparison with DDP, GA, improved ACO, ACO with DR and FCACOA methods, respectively, using less computational effort for solving ten reservoir operation optimization problem. In addition, the computation effort of multi colony ACO and FCPSO were more than triple and twice of $\mathrm{FCGSA}_{I}$ when they were used to solve ten reservoir operation optimization problem. In other words, it is clearly seen form the results of Table 5 that the first formulation of proposed FCGSA (FCGSA ${ }_{I}$ ) shows superior performance to those of other available methods due to the reason discussed follows. In addition, the results produced by FCGSA outperform results produced by other available methods with smaller computational effort. Using this proposed algorithm, the feasible search space of the problem is con- 
structed in which it is much smaller than original search space of the problem. Smaller search space size of the problem leads to better solution with smaller computational effort. In other words, the larger search space size of the problem often requires larger number of samples of the search space to enable the search algorithm to optimize the objective function and therefore it requires larger populations in the population-based search algorithms such as GA and PSO. However, in proposed FCGSA the computational effort is extremely reduced using smaller search space.

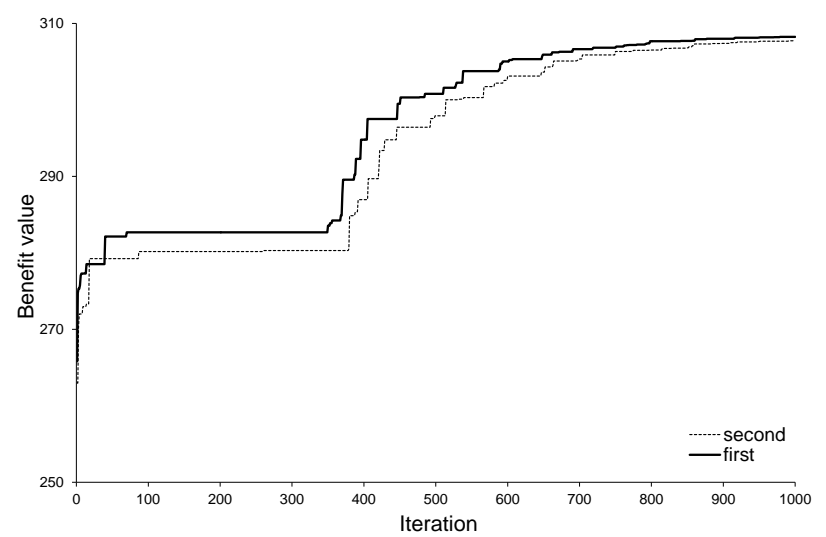

Figure 10. Maximum benefit values versus iterations for fourreservoir system operation problem using first $(I)$ and second (II) formulations of FCGSA.

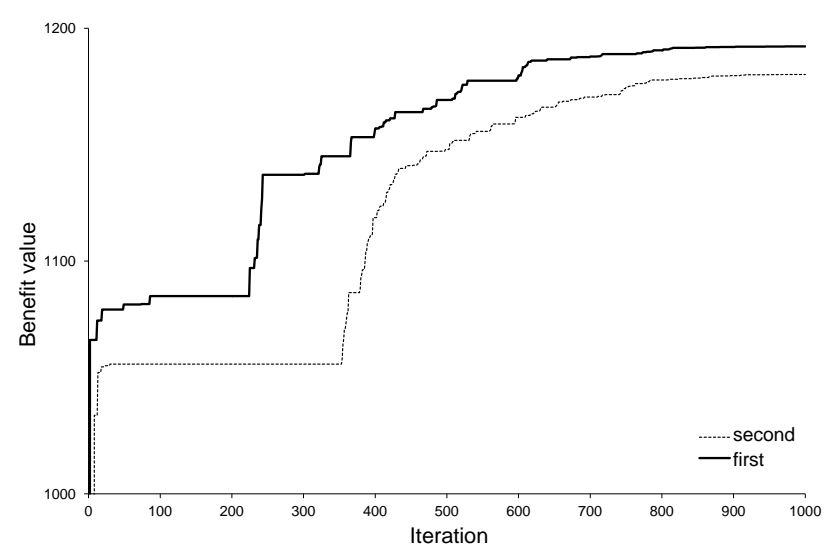

Figure 11. Maximum benefit values versus iterations for tenreservoir systemoperation problem using first $(I)$ and second (II) formulations of FCGSA.

\section{Concluding Remarks}

In this paper, two constrained versions for gravitational search algorithm (GSA) were proposed to solve multi-reservoir operation optimization problem. In the first version (PCGSA), a feasible search space was constructed for each dimension of agent using the decision made at previous dimension such that the continuity equation and the box constraints of water release and storage volumes were simultaneously satisfied. Although the large portion of the infeasible region of the search space was recognized and avoided using PCGSA, however, this algorithm was shown to fail in some rare cases. Therefore, the second version (FCGSA) was proposed in which, in this algorithm, all the constraints of the problem were implicitly satisfied by providing search space for each agent that contains only feasible solution. The FCGSA was shown to be capable of only searching the feasible region of the search space and therefore leading to smaller search space for each agent. Here, two formulations were proposed for these algorithms considering water releases or storage volumes at each operation time period as decision variable of the problem in which they were denoted by suffix $I$ and $I I$, respectively. The proposed algorithms were used to solve the well-known four and ten reservoir operation optimization problems and the results were presented and compared with those of original form of the GSA and any available results in the literature. Results indicated that the proposed constrained algorithms were more effective and efficient than original form of GSA to solve multi-reservoir operation optimization problem. It was also shown that the FCGSA was consistently giving better quality solutions than existing methods with less computational effort in which it led to optimal solutions of 308.238 and 1192.259 for the four and ten reservoir systems, respectively, using first formulation $(I)$ of this algorithm. Finally, it should be noted that the proposed algorithms can be easily used for a real-world large scale multi-objective reservoir operation optimization problem in which the computational cost can be reduced by using the high-performance computing available facilities. Therefore, further research will be done to extend the proposed algorithms to solve multi-objective reservoir operation optimization problem and also it will try to use effective methods such as parallelized algorithm to solve real-world large-scale problem in order to reduce time cost and increase speedup achieving optimal solution.

\section{References}

Azamathulla, H.M., Wu, F.C., Ghani, A.A., Narulkar, S.M., Zakaria, N.A., and Chang, C.K. (2008). Comparison between genetic algorithm and linear programming approach for real time operation. $J$. Hydro-Environ. Res., 2, 172-181. https://doi.org/10.1016/j.jher.2008. 10.001

Afshar, M.H. (2013). Extension of the Constrained Particle Swarm Optimization Algorithm to Optimal Operation of Multi-reservoirs System. Int. J. Electrical Power Energy Syst., 51, 71-81. https://doi.org/ 10.1016/j.ijepes.2013.02.035

Afshar, A., Shafii, M., and Bozorg Haddad, O. (2010). Optimizing multi-reservoir operation rules: an improved HBMO approach. $J$. Hydroinf., 13(1), 121-139. https://doi.org/10.2166/hydro.2010.061

Barros, M.T.L., Tsai, F.T.C., Yang, S.L., Lopes, J.E.G., and Yeh, W. W.G. (2003). Optimization of large-scale hydropower system operations. J. Water Resour. Plan. Manage., 129, 178-188. https://doi. org/10.1061/(ASCE)0733-9496(2003)129:3(178)

Bozorg Haddad, O., Afshar, A., and Mariño, M.A. (2008). Design Operation of Multi-Hydropower Reservoirs: HBMO Approach. Water Resour. Manage., 22(12), 1709-1722. https://doi.org/10.1007/ s11269-008-9249-5

Chen, L. and Chang, F.J. (2007). Applying a real-coded multi-population genetic algorithm to multi-reservoir operation. Hydrol. Process., 21(5), 688-698. https://doi.org/10.1002/hyp.6259

Chow, V.T. and Cortes-Rivera, G. (1974). Application of DDDP in wa- 
ter resources planning.University of Illinois, Water Resources Center, Urbana.

Dariane, A. and Momtahen, S. (2009). Optimization of multireservoir systems operation using modified direct search genetic algorithm. $J$. Water Resour. Plan. Manage., 135, 141-148. https://doi.org/10.1061/ (ASCE)0733-9496(2009)135:3(141)

Esat, V. and Hall, M.J. (1994) Water resource system optimization using genetic algorithms. Hydro informatics'94, pro.,1st Int. Conf. on Hydro informatics, Balkema, Rotterdam, Netherlands, pp.225-231.

Fahmy, H.S., King, J.P., Wentzle, M.W., and Seton, J.A. (1994). Economic optimization of river management using genetic algorithms. American Society of Agricultural Engineers Meeting, St. Joseph, Mich., USA, 1994.

Fallah-Mehdipour, E., Bozorg Haddad, O., and Mariño, M.A. (2011). MOPSO algorithm and its application in multipurpose multi-reservoir operations. J. Hydroinf., 13(4), 794-811. https://doi.org/10. 2166/hydro.2010.105

Goor, Q., Kelman, R., and Tilmant, A. (2011). Optimal multipurposemultireservoir operation model with variable productivity of hydropower plants. J. Water Resour. Plan. Manage., 137(3), 258-267. https://doi.org/10.1061/(ASCE)WR.1943-5452.0000117

Heidari, M., Chow, V.T., Kokotovic, P.V., and Meredith, D.D. (1971). Discrete differential dynamic programming approach to water resources systems optimization. Water Resour. Res., 7(2), 273-282. https://doi.org/10.1029/WR007i002p00273

Hınçal, O., Altan-Sakarya, A.B., and Ger, M. (2011). Optimization of Multireservoir Systems by Genetic Algorithm. Water Resour. Manage., 25 (5), 1465-1487. https://doi.org/10.1007/s11269-010-9755-0

Jalali, M.R. (2005). Optimal design and operation of hydro systems by Ant Colony Algorithms: new heuristic approach. Ph.D. Dissertation, Department of Civil Engineering, Iran University of Science and Technology, Tehran, Iran.

Jalali, M.R., Afshar, A., and Marino, M.A. (2007). Multi-Colony ant Algorithm for Continuous Multi-reservoir Operation Optimization Problems. J. Water Resour. Res., 21(9), 1429-1447. https://doi.org/10. 1007/s 11269-006-9092-5

Jothiprakash, V., Shanthi, G., and Arunkumar, R. (2011). Development of operational policy for a multi-reservoir system in India using genetic algorithm. Water Resour. Manage., 25(10), 2405-2423. https:// doi.org/10.1007/s11269-011-9815-0

Kuczera, G. (1989). Fast multi-reservoir Multi-period Linear programming models. Water Resour. Res., 25(2), 169-176. https://doi.org/ 10.1029/WR025i002p00169

Kumar, D. and Baliarsinch, F. (2003). Folded dynamic programming for optimal operation of multi-reservoir system. Water Resour. Manage., 17(5), 337-353. https://doi.org/10.1023/A:1025894500491

Kumar, D.N. and Reddy, J. (2007). Multipurpose reservoir operation using particle swarm optimization. Water Resour. Plan. Manage., 133(3), 192-201. https://doi.org/10.1061/(ASCE)0733-9496(2007) 133:3(192)

Labadie, J. (2004). Optimal Operation of Multireservoir Systems: Stateof-the-Art Review. Water Resour. Plan. Manage., 130 (2), 93-111. https://doi.org/10.1061/(ASCE)0733-9496(2004)130:2(93)

Larson, R.E. (1968). State Increment dynamic programming. Elsevier Publishing Company Inc. New York.

Liu, P., Cai, X.M., and Guo, S.L. (2011). Deriving multiple near-optimal solutions to deterministic reservoir operation problems. Water Resour. Res., 47(8), 1-20. https://doi.org/10.1029/2011WR010998

Lund, J.R. and Ferreira, I. (1996). Operating rule optimization for Missouri River reservoir system. J. Water Resour. Plan. Manage., 122 (4), 287-295. https://doi.org/10.1061/(ASCE)0733-9496(1996)122: 4(287)

Martin, Q. (1983). Optimal operation of multiple reservoir systems. Water Resour. Plan. Manage., 109 (1), 58-74. https://doi.org/10.1061/ (ASCE)0733-9496(1983)109:1(58)

Malekmohammadi, B., Kerachian, R., and Zahraie, B. (2009). Devel- oping monthly operating rules for a cascade system of reservoirs: application of bayesian networks. Environ. Model. Softw., 24 (12), 1420-1432. https://doi.org/10.1016/j.envsoft.2009.06.008

Moeini, R. (2014). Performance Evaluation of the Ant Colony Optimization Algorithm for the Optimal Operation of a Multi-Reservoir System: Comparing Four Algorithms. Iran-Water Resour. Res., 11 (2), 29-46 [In Persian].

Moeini., R. and Afshar, M.H. (2009) Application of an Ant Colony Optimization Algorithm for optimal operation of reservoirs: A comparative study of three proposed formulations. Sci. Iranica Trans. A Civil Eng., 16 (4), 273-285.

Moeini, R. and Afshar, M.H. (2013). Extension of the constrained ant colony optimization algorithms for the optimal operation of multireservoir systems. J. Hydroinf., 15 (1), 155-173. https://doi.org/10. 2166/hydro.2012.081

Moeini, R., Soltani-nezhad, M., and Daei, M. (2017). Constrained Gravitational Search Algorithm for large scale reservoir operation optimization problem. Eng. Appl. Artificial Intell., 62, 222-233. https://doi.org/10.1016/j.engappai.2017.04.012

Mousavi, J. and Karamouz, M. (2003). Computational improvement for dynamic programming models by diagnosing infeasible storage combinations. Advan. Water Resour., 26(8), 851-859. https://doi.org/ 10.1016/S0309-1708(03)00061-7

Murray, D.M. and Yakowitz, S. (1979). Constrained differential dynamic programming and its application to multireservoir control. Water Resour. Res., 15(5), 1017-1027. https://doi.org/10.1029/WRR015i 005 p01017

Oliveira, R. and Loucks, D. (1997). Operation rules for multi-reservoir systems. Water Resour. Res., 33(4), 839-852. https://doi.org/10.1029 196WR03745

Ostadrahimi, L., Mariño, M.A., and Afshar, A. (2012). Multi- reservoir operation rules: multi-swarm PSO-based optimization approach. WaterResour.Manage., 26(2),407-427.https://doi.org/10.1007/s11269011-9924-9

Perera, B.J.C. and Conder. G.P. (1998). Computational improvement for stochastic dynamic programming models for urban water supply reservoirs. J. Am. Water Resour. Assoc., 34(2), 267-278. https://doi. org/10.1111/j.1752-1688.1998.tb04133.x

Rashedi, E., Nezamabadi-Pour, H., and Saryazdi, S. (2009) GSA: a gravitational search algorithm. Inf. Sci., 179(13), 2232-2248. https: //doi.org/10.1016/j.ins.2009.03.004

Rani, D. and Moreira, M.M. (2010). Simulation-optimization modeling: a survey and potential application in reservoir systems operation. Water Resour Manage., 24(6), 1107-1138. https://doi.org/10. 1007/s11269-009-9488-0

Reis, L.F.R., Bessler, F.T., Walters, G.A., and Savic, D. (2006). Water supply reservoir operation by combined genetic algorithm-linear programming (GA-LP) Approach. Water Resour. Manage., 20 (2), 227-255. https://doi.org/10.1007/s11269-006-8049-Z

Tospornsampan, J., Kita, I., Ishii, M., and Kitamura, Y. (2005a). Optimization of a multiple reservoir system operation using a combination of genetic algorithm and discrete differential dynamic programming: a case study in Mae Klong system, Thailand. Paddy Water Environ., 3 (1), 29-38. https://doi.org/10.1007/s10333-0050070-y

Tospornsampan, J., Kita, I., Ishii, M., and Kitamura, Y. (2005b). Optimization of a multiple reservoir system using a simulated annealingA case study in the Mae Klong system, Thailand. Paddy Water Environ., 3, 137-147. doi:10.1007/s10333-005-0010-x

Trezos, T. (1991). Integer programming application for planning of hydropower production. Water Resour. Plan. Manage., 117(3), 340351. https://doi.org/10.1061/(ASCE)0733-9496(1991)117:3(340)

Tu, M.Y., Hsu, N.S., and Yeh, W.W.G. (2003). Optimization of reservoir management and operation with hedging Rules. Water Resour. Plan. Manage., 129(2), 86-97. https://doi.org/10.1061/(ASCE)0733 -9496(2003)129:2(86) 
Wardlaw, R. and Sharif, M. (1999). Evaluation of genetic algorithms for optimal Reservoir system operation. Water Resour. Plan. Manage.,125(1),25-33.https://doi.org/10.1061/(ASCE)0733-9496(1999) $125: 1(25)$

Wong, K.P. (1994). Short-term hydrothermal scheduling part. I. Simulated annealing approach. IEE Proceedings - Generation, Transmission and Distribution, 141 (5), 497-501, 1994. https://doi.org/10. 1049/ip-gtd:19941350

Yakowitz, S. (1982) Dynamic programming application in water Resources. Water Resour. Res., 18(4), 673-696. https://doi.org/10.1029/ WR018i004p00673
Yeh, W.G. (1985). Reservoir management and operations models: A state-of-the-art review. Water Resour. Res., 21(12), 1797-1818. https: //doi.org/10.1029/WR021i012p01797

Zhao, T.T.G., Cai, X.M., Lei, X.H., and Wang, H. (2012). Improved dynamic programming for reservoir operation optimization with a concave objective function. Water Resour. Plan. Manage., 138(6), 590-596. https://doi.org/10.1061/(ASCE)WR.1943-5452.0000205

Zhang, R., Zhou, J.Z., Ouyang, S., Wang, X.M., and Zhang, H.F. (2013). Optimal operation of multi-reservoir system by multi-elite guide particle swarm optimization. Int. J. Electrical Power Energy Syst., 48(1), 58-68. https://doi.org/10.1016/j.ijepes.2012.11.031 